\title{
Optimal Allocation of FACTS Devices in Distribution Networks Using Imperialist Competitive Algorithm
}

\author{
Mohammad Shahrazad $^{1}$, Ahmed F. Zobaa ${ }^{2}$
}

\begin{abstract}
FACTS devices are used for controlling the voltage, stability, power flow and security of transmission lines. Imperialist Competitive is a recently developed optimization technique, used widely in power systems. This paper presents an approach to finding the optimal location and size of FACTS devices in a distribution network using the Imperialist Competitive technique. IEEE 30bus system is used as a case study. The results show the advantages of the Imperialist Competitive technique over the conventional approaches.
\end{abstract}

Keywords: Imperialist Competitive, FACTS devices, optimization, power quality

\section{Introduction}

Flexible AC Transmission System (FACTS) is a type of static facility, which is used for $A C$ transmission systems to increase stability, flexibility in terms of faults and controllability and to enhance power transfer capability in power networks. It can be observed that by using FACTS, thermal limits in transmission lines will remain constant, eliminating the opportunities for overloading to take place. These devices are also used for power flow, phase, frequency and voltage control [1]. It can be observed that overall losses and also financial cost in the transmission and distribution system for FACTS devices will be reduced, and by optimizing the allocation of FACTS devices in power networks, the total power transfer between buses and also flowing reactive power in networks will be significantly affected. The key parameters in terms of the transmission lines are the placement, the amount and the type of FACTS devices: maximum efficiency in the network will be achieved by optimal allocation of FACTS devices.

Imperialist competitive is used as an optimization method in a variety of different cases and is based on human social evolution [2]. From an economical point of view, it can save energy and increase profit by using FACTS devices in those optimal places. In fact, the novelty of this approach is applying mathematical equations in order to find the optimal placing for FACTS devices as well as the amount and type for each of them. This approach will be more effective in power networks future planning. Several types of FACTS devices are used in power systems, such as: Static Var Compensator (SVC), Thyristor Controlled Series Capacitor (TCSC), Static Synchronous Compensator (STATCOM), Static Synchronous Series Compensator (SSSC) and Unified Power Flow Controller (UPFC) for increasing reliability of the power systems' performance. These types of FACTS devices will be briefly described, as follows: SVC is a compensator that adjusts the reactive power continuously without delay in limited ranges. SVC can regulate the voltage and bring the system towards unity power factor as well. [3]. TCSC is a combination of a bank capacitor which is parallel with a Thyristor controlled reactor, is used for reduction of injected impedance in low frequency and prevents synchronous fluctuations. TCSC has some advantages for the grid such as system stability, voltage regulation and load sharing between the lines and reducing transmission losses [4]. STATCOM could be used for quick control of three phase voltage (amplitude and phase) without applying a voltage $A C$ system; basically, STATCOM is used for a system that has a poor power factor: it is a voltage source converter where the voltage source is created from a $D C$ capacitor, so it has active power capability. SSSC is able to place a voltage with controllable amplitude and phase angle, also it can control power flow and improve power oscillation damping in power networks. Voltage injected by SSSC can be used in series where it is connected and UPFC is used for functional applications; it is a combined static synchronous compensator and static synchronous series compensator that can provide active and reactive power control in the transmission line at the same time [5].

This paper is divided into six sections. Section II explains the imperialist competitive algorithm. Section III gives more information about the algorithm step by step. Section IV indicates objective functions and constraints. In section V, case study and the simulation results are presented, and section VI concludes the paper.

\section{Imperialist Competitive Algorithm}

This section provides information about the IC technique and also the procedure of the algorithm. The ICA is a new heuristic algorithm for global optimization searches that is based on the concept of imperialistic competition [2]. This algorithm is used for mathematical issues; it can be categorized in the same level as GA and 
PSO, and it creates an initial answer, like chromosomes in the GA and particles in the PSO technique. As mentioned earlier, this technique is based on human social evolution, so the initial answer can be assumed as a Country. The base of this algorithm includes assimilation, imperialistic competition and revolution. The algorithm tries to improve the answers and finally arrives at an optimal solution by an iterative procedure.

In this technique, initially ' $n$ ' number of countries is created. Then ' $m$ ' number of the best countries with least cost functions is labeled as the imperialists, whereupon the algorithm distributes the other countries between the empires. Once assimilation is run, a colony will move towards an imperialist by ' $x$ ' unit, which is a random value, and will be placed in a new position [2]. In the algorithm, $\beta$ is the movement co-efficient equal to or greater than 1 , which means that colonies can move towards the empires in different directions. In 'revolution', immediate changes take place between the colonies which causes them to find a better place, in fact the optimal place [2]. After revolution it can be observed that some of the colonies have got a better placement than empires, which means that they can reach some point of function which has less cost: as a result, colonies and empires change positions. Imperialistic competition power is an activity that depends on the other empires and some of the imperialist's own defined colonies. All the empires are in competition and eventually they will each be eliminated. Whenever one empire collapses, its colonies will be distributed to other empires according to their own power. When all the empires have collapsed, only one empire will remain and that means the algorithm has reached the optimal answer [6]. The flowchart of the imperialist competitive algorithm is shown in Fig. 1. IC is the most recently developed optimization technique which is briefly outlined below.

1. Selection of random points on the function and creation of initial empires

2. Moving colonies towards the imperialist (assimilation)

3. Running the revolution operation

4. Exchange positioning of the colonies and imperialist in terms of cost function

5. Calculating the whole cost including imperialists and colonies

6. Collect the weakest colony from the weakest empire and shift to the empire which has more opportunity to grab it

7. Eliminate the weak empire

8. If there is only one empire left then stop, otherwise go to 2

Generally this algorithm is used for different purposes without any limitations. Optimal design of antenna, optimal solution in industrial generation management and optimal design of linear induction machines are some of the activities that can be mentioned [7]. This method is used in the mechanical, management, civil and electrical fields.

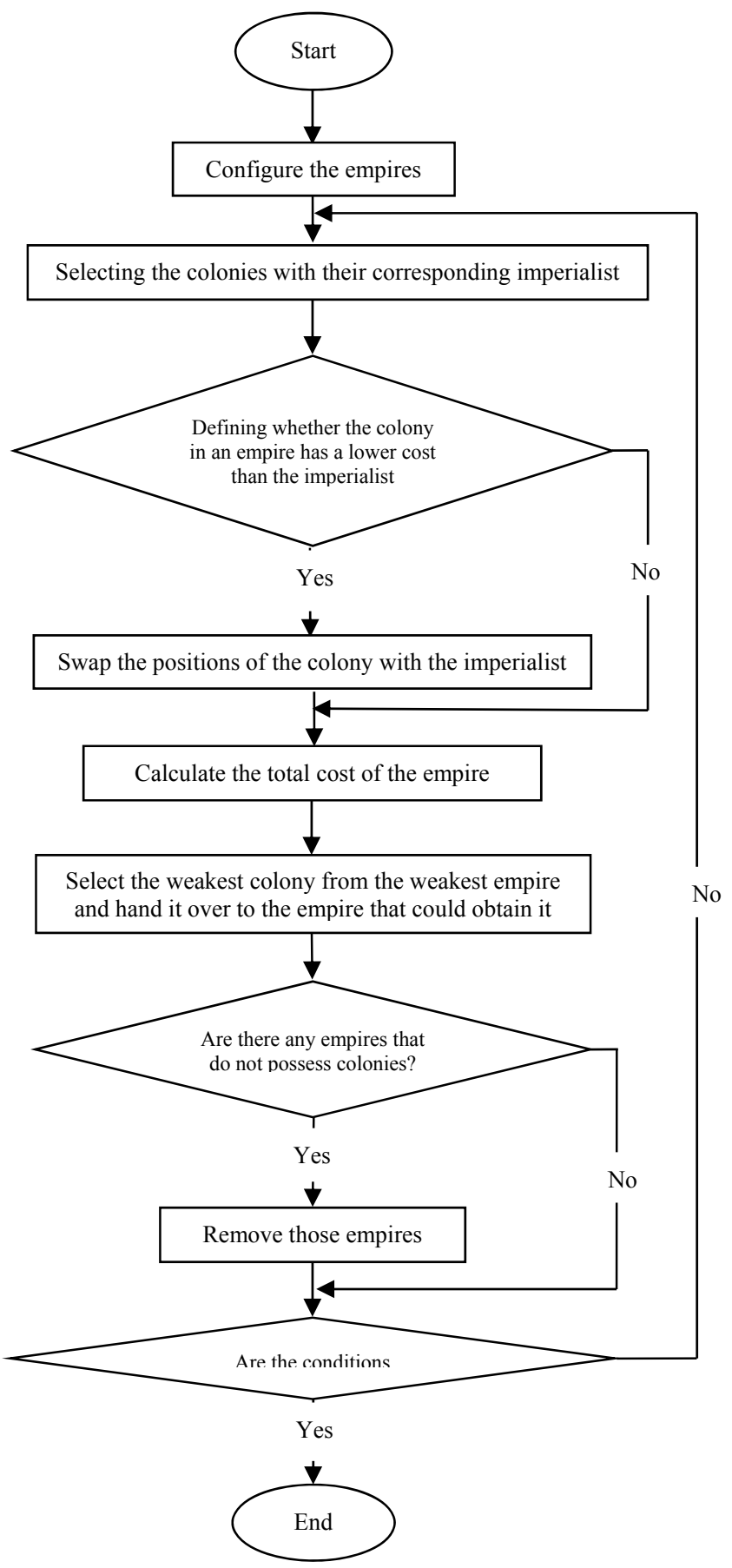

Fig. 1. Flowchart of the imperialist competitive algorithm

\section{Algorithm Definition}

All parameters can be created in terms of problem variables and variable vectors that can be defined as: [2]

$$
\text { Country }=\left[p_{1}, p_{2}, p_{3} \ldots p_{N}\right]
$$

Value of cost function can be defined as: 


$$
\text { Cost }=f \text { (country) }=f\left(p_{1}, p_{2}, p_{3} \ldots p_{N}\right)
$$

In case of controllers function, this can be defined as:

$$
F=w_{1} \times \text { MaxOvershoot }+w_{2} \times I A E
$$

Refer to “(3)," MaxOvershoot represents the maximum of Mutation and $I A E$ represents integrated in the fault. Also $w_{1}$ and $w_{2}$ are types of indexes which show the importance of functions.

In the next step once initial countries were created, algorithm selects some countries which have fewer costs and has advantages over other countries.

$$
C_{n}=c_{n}-\max \left\{c_{i}\right\}, p_{n}=\left|\frac{c n}{\sum_{i=1}^{N i m p} C i}\right|
$$

where $c_{n}$ is the cost function of $\mathrm{n}_{\text {th }}$ Imperialist and $\max \left\{c_{i}\right\}$ is the maximum cost between the Imperialists and $C_{n}$ is the normalized cost for the Imperialist.

The early number of an imperialist's colonies equals with:

$$
N . C_{\cdot n}=\text { round }\left\{p_{n}, N_{c o l}\right\}
$$

where $N . C_{\cdot_{n}}$ is the initial colonies of the one empire and $N_{c o l}$ is the total colonies which do exist and round is the function which gives integer value in case of the decimal value.

In this algorithm once the imperialist is created, other colonies are moved towards the imperialist, in order for colonies are moved from $A$ to $B$. Colony moves toward the imperialist as $X \sim U(0, \beta \times d)$ where, $d$ is the distance between colony and imperialist. Angle deviation will be defined as $\theta \sim U(-\gamma, \gamma)$ where, gamma is the parameter that by increasing the amount of gamma, many places will be searched around the imperialist.This angle causes the increase in seeking the points in the algorithm and $\gamma$ is a parameter which causes to increase the searching points around the empires: therefore colonies will move towards the closest empire. With the consideration of the equation and vector, $\pi / 4$ is a suitable value for $\theta$, and $\beta$ is the value greater than 1 and close to 2 . In optimal cases $\beta$ can be assumed as 2 . If $\beta$ is selected greater than 1 then the colony will move in a different direction towards the empire. Also both the revolution rate and zeta have been considered value of 0.1 . Exploration ability of the algorithm is directly related to revolution. Total power of the Imperialist is defined as:

$$
\begin{aligned}
& T \cdot C_{\cdot n}=\text { Cost }\left(\text { imperialist }_{n}\right)+ \\
& \zeta \text { mean }\left\{\text { Cost }\left(\text { colonies of empire }{ }_{n}\right)\right\}
\end{aligned}
$$

where $\zeta$ is very small value between zero and 1 .

However, in optimal cases it can be assumed $\zeta=0.05$. All the empires have got different total costs. So, they will start to grab their colonies according to their power.
So, the total costs of the empire based on its normalized costs are defined as:

$$
N . T . C_{\cdot n}=\max \left\{T . C_{\cdot_{i}}\right\}-T . C_{\cdot_{n}}
$$

where T.C.n is total cost of $n_{t h}$ empire and N.T.C.n is normalized of total cost of same empire.

So, if any empire has less T.C.n then it will have more N.T.C.n.

The probability of the possession of colonies is defined as:

$$
P_{\mathrm{p} n}=\left|\frac{N . T . C . n}{\sum_{i=1}^{N i m p} \text { N.T.C.i }}\right|
$$

With considering the probability of the possession, the algorithm distributes the colonies according to the power of the empires. Vector $P$ can be created from the above probability levels:

$$
P=\left[P p_{1}, P p_{2}, P p_{3}, \ldots, P p_{N(i m p)}\right]
$$

This vector has the size of $1 \times N_{\text {imp }}$ and includes all the probability of the possession values of the empires. In this regard, vector $R$ should be created to the same size. Arrays of this type of vector have a random value between 0 and $1, r_{1}, r_{2}, r_{3}, \ldots, r_{N(i m p)} \sim U(0,1)$.

$$
\begin{gathered}
R=\left[r_{1}, r_{2}, r_{3}, \ldots, r_{N(i m p)}\right] \\
D=P-R=\left[D_{1}, D_{2}, D_{3}, \ldots, D_{N(i m p)}\right] \\
=\left[P p_{1}-r_{1}, P p_{2}-r_{2}, P p_{3}-r_{3}, \ldots, P p_{N(i m p)}-r_{N(i m p)}\right]
\end{gathered}
$$

With obtaining the $D$ vector the empire will grab their colonies according to the value which is in the $D$. In this case weak empires will collapse and their colonies will distribute to the other empires until one empire is left and the algorithm finds the optimum answer and finishes.

\section{Objective Functions and Constraints}

In this case, two objective functions have been involved. Firstly minimize the voltage deviation and secondly minimize the FACTS size. The two elements $J_{1}$ and $J_{2}$ are defined as [10]:

$$
J_{1}=V_{d}=\sqrt{\sum_{i=1}^{N b u s}\left(V_{i}-1\right)_{i}-1}
$$

where, $J_{1}$ is the voltage deviation and $V_{i}$ is the voltage magnitude,

$$
J_{2}=\sum_{j=1}^{\text {Nunits }} \eta_{j}
$$

where, $J_{2}$ is the FACTS size, $\eta_{j}$ is the size in MVar of FACTS and Nunits is the number of FACTS should be allocated. Also constraints can be defined as:

$$
\left|V_{i}\right|_{\min } \leq\left|V_{i}\right| \leq\left|V_{i}\right|_{\max }
$$




$$
S_{i j} \leq S_{i j m a x}, \delta_{i j} \leq \delta_{i j m a x}
$$

where, $\left|V_{i}\right|_{\min },\left|V_{i}\right|_{\max }$ are minimum and maximum voltage magnitude at bus $i, S_{i j}$ is the apparent power of the line $i, j$ and $S_{i j m a x}$ is the thermal limit of the line $i, j$ and $\delta_{i j}$ is The difference of phase angel between buses $i, j$. In this case, long and short and emergency rating have been considered as a value of $250 \mathrm{MVA}$. Maximum and minimum reactive power output of the generator has been assumed between -999 and 999 MVar. Maximum and minimum voltage magnitude assumed between 0.95 and 1.05 p.u. and total MVA base of machine has considered $100 \mathrm{MVA}$.

The mathematical equation of power flow with FACTS devices can be defined as:

$$
\begin{gathered}
P_{G i}-P_{D i}-\sum_{j=1}^{n}\left|V_{i}\right|\left|V_{j}\right|\left(G_{i j(F A C T S)} \cos \delta_{i j}+B_{i j(\text { FACTS })}\right. \\
\left.\sin \delta_{i j}\right)=0 \\
Q_{G i}-Q_{D i}-\sum_{j=1}^{n}\left|V_{i}\right|\left|V_{j}\right|\left(G_{i j(F A C T S)} \sin \delta_{i j}-B_{i j(F A C T S)}\right. \\
\left.\cos \delta_{i j}\right)=0
\end{gathered}
$$

where $P_{G i}$ and $Q_{G i}$ are generated real and reactive power at bus $i, P_{D i}$ and $Q_{D i}$ are real and reactive power of the load at bus $i, G_{(i j F A C T S)}$ is real part of admittance (Conductance) of network including FACTS devices and $B_{(i j F A C T S)}$ is imaginary part of admittance (Susceptance) of network includes FACTS devices, $n$ is number of buses .

According to the electrical circuit rules, all equations regarding injected active and reactive power into transmission lines between buses with installing FACTS devices can be defined as [8]:

$$
\begin{aligned}
P_{i c} & =V_{i}^{2} \Delta G_{i j}-V_{i} V_{j}\left[\Delta G_{i j} \cos \delta_{i j}+\Delta B_{i j} \sin \delta_{i j}\right] \\
P_{j c} & =V_{j}^{2} \Delta G_{i j}-V_{i} V_{j}\left[\Delta G_{i j} \cos \delta_{i j}-\Delta B_{i j} \sin \delta_{i j}\right] \\
Q_{i c} & =-V_{i}^{2} \Delta B_{i j}-V_{i} V_{j}\left[\Delta G_{i j} \sin \delta_{i j}-\Delta B_{i j} \cos \delta_{i j}\right] \\
Q_{j c} & =-V_{j}^{2} \Delta B_{i j}+V_{i} V_{j}\left[\Delta G_{i j} \sin \delta_{i j}+\Delta B_{i j} \cos \delta_{i j}\right]
\end{aligned}
$$

There are 3 parameters defined along the allocation of FACTS devices in transmission lines:

a) Index of losses in the sensitivity of transmission lines

$$
a_{k}=\partial P_{L k} / \partial x_{k} \mid x_{k}=0
$$

b) Index of losses sensitivity of whole system [9]

$P_{L T}=\sum_{j=1}^{N} \sum_{k=1}^{N}\left[\alpha_{j k}\left(P_{j} P_{k}+Q_{j} Q_{k}\right)+\beta_{j k}\left(Q_{j} P_{k}-P_{j} Q_{k}\right)\right]$

where $\alpha_{j k}$ and $\beta_{j k}$ are the loss coefficients which are:

$$
\begin{aligned}
& \alpha_{j k}=r_{j k} / V_{j} V_{k} * \cos \left(\delta_{j}-\delta_{k}\right) \\
& \beta_{j k}=r_{j k} / V_{j} V_{k} * \sin \left(\delta_{j}-\delta_{k}\right)
\end{aligned}
$$

where $r_{j k}$ is the real part of the $j k$ element of impedance matrix.

c) Index of real power flow ability

$$
P I=\sum_{m=1}^{N} \frac{W m}{2 n}\left(P_{\operatorname{lm}} / P_{\operatorname{lm}(\max )}\right)^{2 n}
$$

where $P_{l m}$ and $P_{l m(\max )}$ are the flowing power and maximum flowing power of the $m$ transmission, $w_{m}$ is the weight co-efficient and $n$ in this case is considered 2 .

The total power loss equation is given:

$$
P_{l}=\sum\left[V_{i}^{2}+V_{j}^{2}-2 V_{i} V_{j} \cos \left(\delta_{i}-\delta_{j}\right)\right] Y_{i j} \cos \varphi_{i j}
$$

where $\delta_{i}$ is the angle of the voltage at bus $i, Y_{i j}$ and $\varphi_{i j}$ are the magnitude and angle of the admittance of the transmission lines at $i, j$.

For computing total transfer capability is defined. The real power generations at bus $i\left(P_{G i}\right)$ which is in the source area and real and reactive load demand at bus $i$ $\left(P_{D i} \& Q_{D i}\right)$ which are in the sink area in function of $\lambda$ follow these equations:

$$
\begin{aligned}
& P_{G i}=P_{G i}+\left(1+\lambda k_{G i}\right) \\
& P_{D i}=P_{D i}+\left(1+\lambda k_{D i}\right) \\
& Q_{D i}=Q_{D i}+\left(1+\lambda k_{Q i}\right)
\end{aligned}
$$

$k_{G i}$ and $k_{D i}$ are the constant used to show the rate of changes in load with various $\lambda$.

The total transfer capability is defined [11]:

$$
T T C=\sum_{i=1} P_{D i}\left(\lambda_{\max }\right)-\sum_{i=1} P_{D i}^{0}
$$

in this case, $P_{D i}\left(\lambda_{\max }\right)$ is the sum of the load in sink area whether $\lambda=\lambda_{\max }$. On the other hand $P^{0}{ }_{D i}$ is the sum of load where $\lambda=0$.

\section{Case Study}

IEEE 30 bus test system has been considered as a case study [12]. Fig. 2 illustrates a schematic of the network [12]. Considering the IEEE 30 bus system, a comparison of the simulated results which have been obtained before with other optimization methods will reveal their advantages and disadvantages. This section will present all the related results regarding allocation of FACTS devices. In this case some comparison has been done with other methods: PSO, GA, BFA, Benders and B\&B are the methods which have been run on the power systems and results are shown in Table I It can be observed that there are advantages in terms of the time, 
particularly for convergence characteristics in finding the placement of FACTS devices.

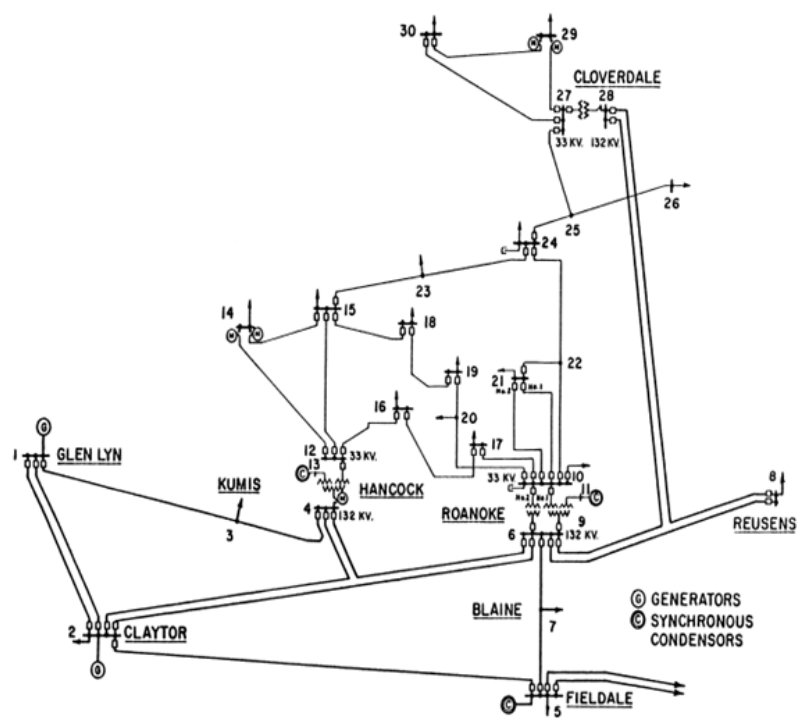

Fig. 2. IEEE 30 bus study case

Also the number of power flows is another factor that can reduce the time of convergence. Importantly there are two buses which need to be considered, as they will cause an increase in the installation cost of FACTS devices compared to using only one. Voltage improvement throughout the power network is feasible. To achieve total transfer capability in the power systems, initially load is increased gradually until one of the constraints is reached.

TABLE I

Summary of PERformance Allocation of FACts Devices [10]

\begin{tabular}{ccccccc}
\hline \hline Method & $\begin{array}{c}\text { Bus } \\
1\end{array}$ & $\begin{array}{c}\text { Size 1 } \\
\text { (Mvar) }\end{array}$ & $\begin{array}{c}\text { Bus } \\
2\end{array}$ & $\begin{array}{c}\text { Size 2 } \\
\text { (Mvar) }\end{array}$ & Time(S) & $\begin{array}{c}\text { No of } \\
\text { PF }\end{array}$ \\
\hline PSO & 26 & 50 & 30 & 62 & 546 & 1200 \\
GA & 26 & 50 & 30 & 62 & 525 & 1200 \\
BFA & 26 & 51 & 30 & 62 & 8,453 & 1200 \\
Benders & 26 & 50 & 30 & 62 & 16,463 & 58058 \\
B\&B & 26 & 42 & 30 & 62 & 735 & 1316 \\
IC & 24 & 77.5 & - & - & 387 & 300 \\
\hline \hline
\end{tabular}

Several advantages can be seen with optimizing the system using Imperialist Competitive. Firstly, this can improve the total transfer capability and secondly, it can reduce losses. In this regard there are two objective functions that have been considered: voltage deviation and FACTS size, which have the same number of objective functions. The number of iterations is considered to be 100 , which was defined as the stopping criterion in the program. Regarding the SVC component, the program found one place. Bus 24 with value of 77.5 $M V A r$ has been found.

TABLE II

SUMMARY OF THE LOAD FLOW

\begin{tabular}{|c|c|c|c|c|}
\hline \multirow{3}{*}{$\begin{array}{l}\text { Bus } \\
\text { No. }\end{array}$} & \multicolumn{2}{|c|}{ Generation } & \multicolumn{2}{|r|}{ Load } \\
\hline & Real power (p.u.) & Reactive power (p.u.) & Real power (p.u.) & Reactive power (p.u.) \\
\hline & & & & \\
\hline 1 & 1.3848 & -0.028 & 0.000 & 0.000 \\
\hline 2 & 0.39 & 0.51 & 0.216 & 0.128 \\
\hline 3 & 0.000 & 0.000 & 0.025 & 0.011 \\
\hline 4 & 0.000 & 0.000 & 0.075 & 0.015 \\
\hline 5 & 0.000 & 0.380 & 0.941 & 0.180 \\
\hline 6 & 0.000 & 0.000 & 0.000 & 0.000 \\
\hline 7 & 0.000 & 0.000 & 0.227 & 0.108 \\
\hline 8 & 0.000 & 0.372 & 0.200 & 0.200 \\
\hline 9 & 0.000 & 0.000 & 0.000 & 0.000 \\
\hline 10 & 0.000 & 0.000 & 0.057 & 0.010 \\
\hline 11 & 0.000 & 0.161 & 0.000 & 0.000 \\
\hline 12 & 0.000 & 0.000 & 0.113 & 0.076 \\
\hline 13 & 0.000 & 0.105 & 0.000 & 0.000 \\
\hline 14 & 0.000 & 0.000 & 0.061 & 0.015 \\
\hline 15 & 0.000 & 0.000 & 0.083 & 0.026 \\
\hline 16 & 0.000 & 0.000 & 0.340 & 0.017 \\
\hline 17 & 0.000 & 0.000 & 0.080 & 0.057 \\
\hline 18 & 0.000 & 0.000 & 0.033 & 0.008 \\
\hline 19 & 0.000 & 0.000 & 0.096 & 0.035 \\
\hline 20 & 0.000 & 0.000 & 0.021 & 0.006 \\
\hline 21 & 0.000 & 0.000 & 0.176 & 0.113 \\
\hline 22 & 0.000 & 0.000 & 0.000 & 0.000 \\
\hline 23 & 0.000 & 0.000 & 0.033 & 0.017 \\
\hline 24 & 0.000 & 0.000 & 0.088 & 0.068 \\
\hline 25 & 0.000 & 0.000 & 0.000 & 0.000 \\
\hline 26 & 0.000 & 0.000 & 0.034 & 0.022 \\
\hline 27 & 0.000 & 0.000 & 0.000 & 0.000 \\
\hline 28 & 0.000 & 0.000 & 0.000 & 0.000 \\
\hline 29 & 0.000 & 0.000 & 0.023 & 0.008 \\
\hline 30 & 0.000 & 0.000 & 0.107 & 0.020 \\
\hline
\end{tabular}


Table II indicates a summary of load flow. In this case the program analyzed the system using Newton-Raphson to load flow. Newton-Raphson is one of the fastest convergence methods to the root; also the method of convergence is quadratic. Voltage deviation is one of the major issues which all industries must also consider; voltage level can be divided from a millisecond to a few seconds. Therefore, installing the FACTS devices in different places can solve the voltage sag problem and supply a high quality of power in the network. Table III indicates the summary of performance data based on TTC. It can be seen that level of losses decreased and total transfer capability in power systems was enhanced.

TABLE III

SumMary OF PERFormance Data BASED ON TTC

\begin{tabular}{cccc}
\hline \hline Method & TTC (\%) & $\begin{array}{c}\text { Voltage } \\
\text { deviation }\end{array}$ & $\begin{array}{c}\text { Loss reduction } \\
(\%)\end{array}$ \\
\hline IC & 25.33 & 0.007 & 5.61 \\
\hline \hline
\end{tabular}

Table III shows the system total transfer capability and voltage deviation and loss reduction. In this case installing FACTS devices in bus 24 with obtained amount can reduce the total loss reduction by $5.61 \%$. The following figures show the level of voltage after optimization and also the number of iterations for finding FACTS devices in transmission lines. Voltage profile is one of the most important issues in power networks, as fluctuation of load variation in the power network causes systems to be stressed. By adjusting the transformer tap ratio and installing FACTS devices, losses can be reduced and the voltage profile improved [13]. Usually 5 to 13 percent of power in a distribution network is wasted as heat; this is because of the high current in medium and low voltage in comparison with high voltage transmission lines. The following figures demonstrate the profile voltage before and after optimization by ICA.

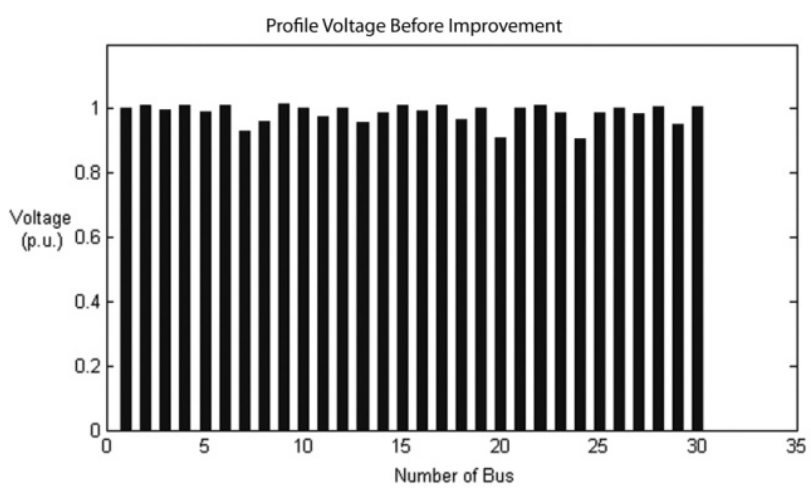

Fig. 3. Level of voltage before optimization by imperialist competitive

The level of the voltage before and after optimization by ICA is shown in Fig. 3 and Fig. 4. In any condition, power systems should be stable according to various operational criteria. Voltage collapse is one of the major phenomena which take place in transmission systems; in this case, voltage is decreasing gradually until the system is going to shut down. Also in the case of a small amount of overload, voltage will decrease slightly but in a case of massive overload, voltage will descend significantly.

Fig. 4 indicates the level of voltage after installing the FACTS in the power systems. In Fig. 4 it can be seen that voltage remained stable.

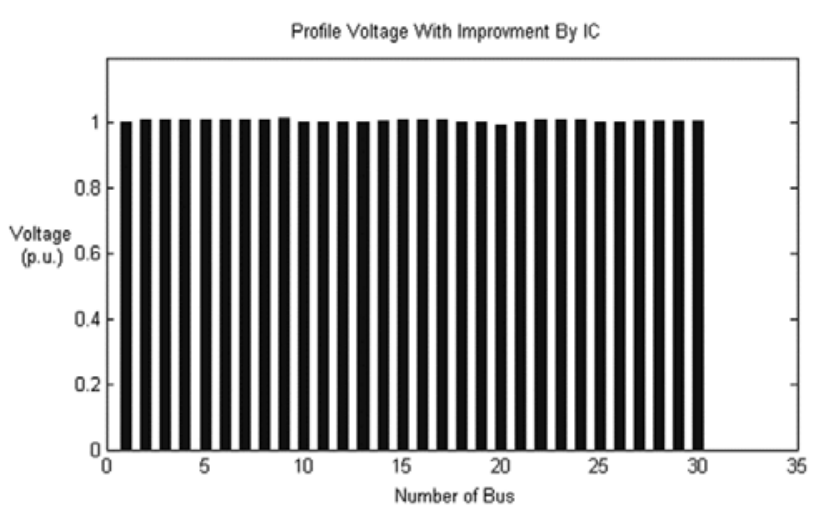

Fig. 4. Level of voltage after optimization by imperialist competitive

By installing FACTS in the power system, it can be observed that the level of voltage in bus 7, 8, 13, 20 and 24 improved. The only way to prevent voltage collapse in power systems is by controlling the reactive power in the network. Another feature of the FACTS is their quick response to any change in the system.

Before running the program, it should be confirmed which size of FACTS is available in the power market. Many researches have been carried out regarding the allocation of FACTS and the best place for FACTS allocation has been shown to be in the middle of the transmission lines.

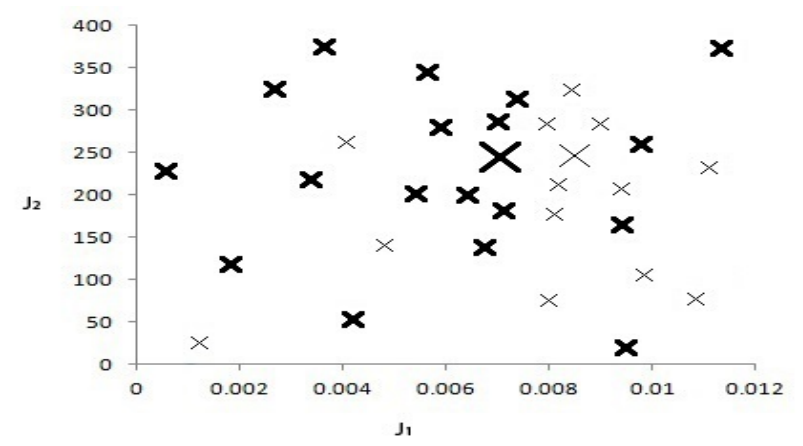

Fig. 5. Position of empires after 30 iterations

Fig. 5 indicates the position of the empires after 30 iterations. It can be seen that two empires remain and there is a tight competition between them. The horizontal and vertical axes represent voltage deviation and FACTS size respectively. Also, the stronger empire as indicated by a larger $x$ symbol.

The convergence characteristics are given in Fig. 6, it can be seen that the algorithm has a better feather to find the optimal allocation of FACTS devices. Because of 
complex space search, some of the optimization methods fail to converge, but with the Imperialist Competitive algorithm it is possible to arrive at the proper and optimal solution.

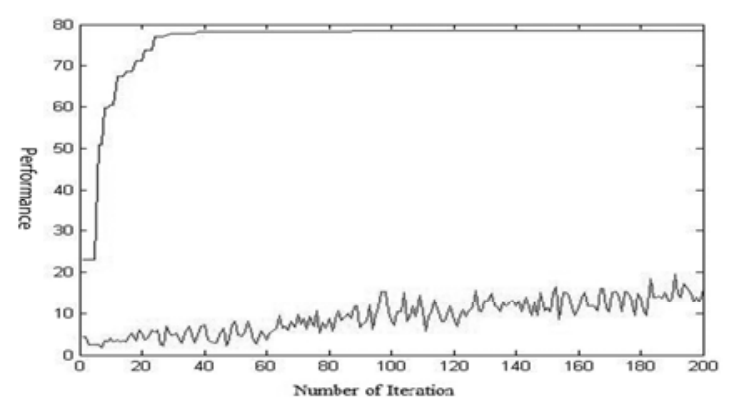

Fig. 6. Convergence of imperialist competitive for allocation of FACTS

Fig. 7 and Fig. 8 indicate levels of the maximum and mean performance during the iteration.

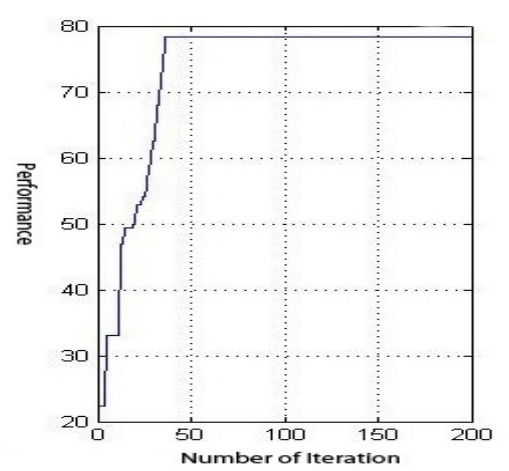

Fig. 7. Maximum performance at each iteration

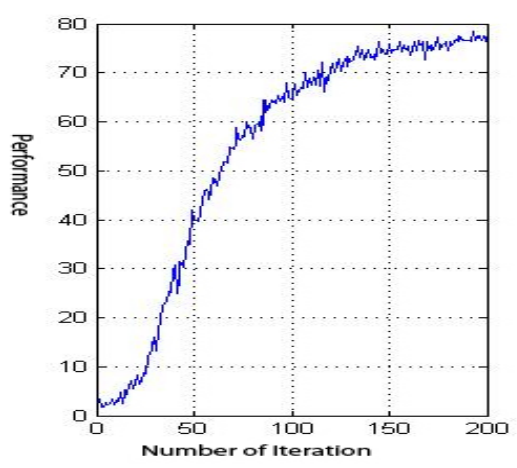

Fig. 8. Mean performance at each iteration

These graphs depend on the co-efficient value in the program. However, with changing those values, level of the graphs will be changed. Refer to Fig. 8 it can be observed that algorithm reached the peak performance after 200 iterations.

\section{Conclusions}

This paper presents the application of the imperialist competitive algorithm in finding the optimal location and size of FACTS devices in distribution networks. The results show the effectiveness of this approach. The IEEE 30-bus system is used as a case study in this paper. It can be seen that it is possible to minimize the total losses and with a higher efficiency. Simulation results on the multiobjective optimization problem for minimization of total cost and enhancement of system load-ability using imperialist competitive algorithm are quite encouraging. Feasible enhancement in load-ability while achieving minimum cost is observed in the results obtained through imperialist competitive algorithm, when compared with other methods though other methods are not faster than imperialist competitive algorithm. The results help in planning the FACTS placement to minimize the financial cost and maximize power transfer capability in the power networks.

\section{References}

[1] A-A. Edris, Adapa, M. H.Baker, L. Bohmann K. Clark, J. Lemay, A. S. Mehraban, J. Reeve, F. Sener, R.R.Wood, Proposed terms and definitions for flexible AC transmission system(FACTS), IEEE Transactions on Power Delivery, Volume 12, Issue 4, October 1997, pp. 1848-1853

[2] Atashpaz-Gargari, E.; Lucas, C (2007). Imperialist Competitive Algorithm: An algorithm for optimization inspired by imperialistic competition, IEEE Congress on Evolutionary Computation. 7. pp. 4661-4666.

[3] De Kock, Jan; Practical Power Distribution for Industry, (Strauss, Cobus (2004).. Elsevier. pp. 74-75).

[4] R.Grunbaum and Jcques Pernot, "Thyristor-Controlled series Compensation: A state of the Art Approach for Optimization of Transmission Over Power Links. Internet: http://www05.abb.com/global/scot/scot221.nsf/veritydisplay/d5 78889d05b3ba01c1256fda003b4cff/\$file/SEE FIILE2001_TCS C.pdf, 10,03,2013.

[5] N. G. Hingorani, L. Gyugyi, Understanding FACTS; Concepts and Technology of Flexible AC Transmission Systems,(IEEE Press book, 2000).

[6] Rajabioun, R.; Atashpaz-Gargari, E.; Lucas, C. (2008). Colonial competitive algorithm as a tool for Nash equilibrium point achievement. Computational Science and Its Applications-ICCSA. pp. 680-695.

[7] F. Jolai, M. Sangari, and M. Babaie, Pareto simulated annealing and colonial competitive algorithm to solve an offline scheduling problem with rejection, Proceedings of the Institution of Mechanical Engineers, Part B: Journal of Engineering Manufacture, pp. 1-13.

[8] K. S. Verma, S. N. Singh, and H. O. Gupta, FACTS Devices Location for Enhancement of Total Transfer Capability, IEEE Power Engineering Society Winter Meeting, Vol. 2, pp. 522527, 2001.

[9] J. Baskaram, V. Palanisamy, Optimal Location of FACTS Devices in a Power System Solved by a Hybrid Approach, Elsevier Nonlinear Analysis 65(2094-2102),2006.

[10] Ravi, K. and Rajaram, M. Optimal location of FACTS devices using enhanced particle swarm optimization, in Advanced Communication Control and Computing Technologies (ICACCCT), 2012 IEEE International Conference on, 23-25 Aug. 2012, pp. $414-419$. 
[11] G. C. Ejebe, J. G. Waight, S. N. Manuel, and W. F. Tinney, Fast calculation of linear available transfer capability, IEEE Trans. Power Syst., Vol. 15, No. 3, pp. 1112-1116, August 2000.

[12] Iraj Dabbagchi of AEP and entered in IEEE Common Data Format by Rich Christie at the University of Washington in August 1993.

Internet: http://www.ee.washington.edu/research/pstca/ ,10,06
2013.

[13] Seungwon An and Thomas W. Gedra, An Ideal Transformer UPFC Model, OPF First-Order Sensitivities and Application to Screening for Optimal UPFC Locations, IEEE Transactions on Power Systems, Vol. 22, no. 1, February 2007.

\section{Appendix A}

TABLE A1

SUMMARY OF THE BRANCH DATA

\begin{tabular}{|c|c|c|c|c|c|c|c|c|c|c|}
\hline F_Bus & T_Bus & $\mathrm{R}$ & $\mathrm{X}$ & $\mathrm{B}_{\mathrm{T}}$ & $\mathrm{S}_{\mathrm{LT}}$ & $\mathrm{S}_{\mathrm{ST}}$ & $\mathrm{S}_{\mathrm{E}}$ & Tap & $\delta$ & BR_Status \\
\hline 1 & 2 & 0.0192 & 0.0575 & 0.0528 & 0 & 0 & 0 & 0.0 & 0.0 & 1 \\
\hline 1 & 3 & 0.0452 & 0.1652 & 0.0408 & 0 & 0 & 0 & 0.0 & 0.0 & 1 \\
\hline 2 & 4 & 0.0570 & 0.01737 & 0.0368 & 0 & 0 & 0 & 0.0 & 0.0 & 1 \\
\hline 3 & 4 & 0.0132 & 0.0379 & 0.0084 & 0 & 0 & 0 & 0.0 & 0.0 & 1 \\
\hline 2 & 5 & 0.0472 & 0.1983 & 0.0418 & 0 & 0 & 0 & 0.0 & 0.0 & 1 \\
\hline 2 & 6 & 0.0581 & 0.1763 & 0.0374 & 0 & 0 & 0 & 0.0 & 0.0 & 1 \\
\hline 4 & 6 & 0.0119 & 0.0414 & 0.0090 & 0 & 0 & 0 & 0.0 & 0.0 & 1 \\
\hline 5 & 7 & 0.0460 & 0.1160 & 0.0204 & 0 & 0 & 0 & 0.0 & 0.0 & 1 \\
\hline 6 & 7 & 0.0267 & 0.0820 & 0.0170 & 0 & 0 & 0 & 0.0 & 0.0 & 1 \\
\hline 6 & 8 & 0.0120 & 0.0420 & 0.0090 & 0 & 0 & 0 & 0.0 & 0.0 & 1 \\
\hline 6 & 9 & 0.0 & 0.2080 & 0.0 & 0 & 0 & 0 & 0.978 & 0.0 & 1 \\
\hline 6 & 10 & 0.0 & 0.5560 & 0.0 & 0 & 0 & 0 & 0.969 & 0.0 & 1 \\
\hline 9 & 11 & 0.0 & 0.2080 & 0.0 & 0 & 0 & 0 & 0.0 & 0.0 & 1 \\
\hline 9 & 10 & 0.0 & 0.1100 & 0.0 & 0 & 0 & 0 & 0.0 & 0.0 & 1 \\
\hline 4 & 12 & 0.0 & 0.2560 & 0.0 & 0 & 0 & 0 & 0.932 & 0.0 & 1 \\
\hline 12 & 13 & 0.0 & 0.1400 & 0.0 & 0 & 0 & 0 & 0.0 & 0.0 & 1 \\
\hline 12 & 14 & 0.1231 & 0.2559 & 0.0 & 0 & 0 & 0 & 0.0 & 0.0 & 1 \\
\hline 12 & 15 & 0.0662 & 0.1304 & 0.0 & 0 & 0 & 0 & 0.0 & 0.0 & 1 \\
\hline 12 & 16 & 0.0945 & 0.1987 & 0.0 & 0 & 0 & 0 & 0.0 & 0.0 & 1 \\
\hline 14 & 15 & 0.2210 & 0.1997 & 0.0 & 0 & 0 & 0 & 0.0 & 0.0 & 1 \\
\hline 16 & 17 & 0.524 & 0.1923 & 0.0 & 0 & 0 & 0 & 0.0 & 0.0 & 1 \\
\hline 15 & 18 & 0.1073 & 0.2185 & 0.0 & 0 & 0 & 0 & 0.0 & 0.0 & 1 \\
\hline 18 & 19 & 0.0639 & 0.1292 & 0.0 & 0 & 0 & 0 & 0.0 & 0.0 & 1 \\
\hline 19 & 20 & 0.0340 & 0.0680 & 0.0 & 0 & 0 & 0 & 0.0 & 0.0 & 1 \\
\hline 10 & 20 & 0.0936 & 0.2090 & 0.0 & 0 & 0 & 0 & 0.0 & 0.0 & 1 \\
\hline 10 & 17 & 0.0324 & 0.0845 & 0.0 & 0 & 0 & 0 & 0.0 & 0.0 & 1 \\
\hline 10 & 21 & 0.0348 & 0.0749 & 0.0 & 0 & 0 & 0 & 0.0 & 0.0 & 1 \\
\hline 10 & 22 & 0.0727 & 0.1499 & 0.0 & 0 & 0 & 0 & 0.0 & 0.0 & 1 \\
\hline 21 & 22 & 0.0116 & 0.0236 & 0.0 & 0 & 0 & 0 & 0.0 & 0.0 & 1 \\
\hline 15 & 23 & 0.1000 & 0.2020 & 0.0 & 0 & 0 & 0 & 0.0 & 0.0 & 1 \\
\hline 22 & 24 & 0.1150 & 0.1790 & 0.0 & 0 & 0 & 0 & 0.0 & 0.0 & 1 \\
\hline 23 & 24 & 0.1320 & 0.2700 & 0.0 & 0 & 0 & 0 & 0.0 & 0.0 & 1 \\
\hline 24 & 25 & 0.1885 & 0.3292 & 0.0 & 0 & 0 & 0 & 0.0 & 0.0 & 1 \\
\hline 25 & 26 & 0.2544 & 0.3800 & 0.0 & 0 & 0 & 0 & 0.0 & 0.0 & 1 \\
\hline 25 & 27 & 0.1093 & 0.2087 & 0.0 & 0 & 0 & 0 & 0.0 & 0.0 & 1 \\
\hline 28 & 27 & 0.0 & 0.3960 & 0.0 & 0 & 0 & 0 & 0.968 & 0.0 & 1 \\
\hline 27 & 29 & 0.2198 & 0.4153 & 0.0 & 0 & 0 & 0 & 0.0 & 0.0 & 1 \\
\hline 27 & 30 & 0.3202 & 0.6027 & 0.0 & 0 & 0 & 0 & 0.0 & 0.0 & 1 \\
\hline 29 & 30 & 0.2399 & 0.4533 & 0.0 & 0 & 0 & 0 & 0.0 & 0.0 & 1 \\
\hline 8 & 28 & 0.0636 & 0.2000 & 0.0428 & 0 & 0 & 0 & 0.0 & 0.0 & 1 \\
\hline 6 & 28 & 0.0169 & 0.0599 & 0.0130 & 0 & 0 & 0 & 0.0 & 0.0 & 1 \\
\hline
\end{tabular}

TABLE A2

SUMMARY OF THE GENERATOR DATA

\begin{tabular}{cccccccccc}
\hline \hline $\mathrm{N}$ & $\mathrm{P}_{\mathrm{G}}$ & $\mathrm{Q}_{\mathrm{G}}$ & $\mathrm{Q}_{\max }$ & $\mathrm{Q}_{\min }$ & $\mathrm{V}_{\mathrm{G}}$ & $\mathrm{M}_{\text {base }}$ & Gen_Status & $\mathrm{P}_{\max }$ & $\mathrm{P}_{\min }$ \\
\hline 1 & 250 & 0 & 999 & -999 & 1.04 & 100 & 1 & 250 & 10 \\
2 & 545 & 0 & 999 & -999 & 0.98 & 100 & 1 & 300 & 10 \\
13 & 650 & 0 & 999 & -999 & 0.983 & 100 & 1 & 270 & 10 \\
22 & 632 & 0 & 999 & -999 & 0.997 & 100 & 1 & 250 & 10 \\
23 & 505.2 & 0 & 999 & -999 & 1.011 & 100 & 1 & 300 & 10 \\
27 & 700 & 0 & 999 & -999 & 1.05 & 100 & 1 & 270 & 10 \\
\hline \hline
\end{tabular}


TABLE A3

SuMMARY OF THE BUS DATA

\begin{tabular}{|c|c|c|c|c|c|c|c|c|c|c|c|c|}
\hline Bus_I & Bus_Type & $\mathrm{P}_{\mathrm{D}}$ & $\mathrm{Q}_{\mathrm{D}}$ & $\mathrm{G}$ & $\mathrm{B}$ & Bus_Area & $\mathrm{V}_{\mathrm{M}}$ & $\mathrm{V}_{\mathrm{A}}$ & Base_KV & Zone & Vmax & Vmin \\
\hline 1 & 3 & 0.0 & 0.0 & 0.0 & 0.0 & 1 & 1.060 & 0.0 & 132 & 1 & 1.05 & 0.95 \\
\hline 2 & 2 & 21.7 & 12.7 & 0.0 & 0.0 & 1 & 1.043 & -5.48 & 132 & 1 & 1.05 & 0.95 \\
\hline 3 & 1 & 2.4 & 1.2 & 0.0 & 0.0 & 1 & 1.021 & -7.96 & 132 & 1 & 1.05 & 0.95 \\
\hline 4 & 1 & 7.6 & 1.6 & 0.0 & 0.0 & 1 & 1.012 & -9.60 & 132 & 1 & 1.05 & 0.95 \\
\hline 5 & 2 & 19.4 & 19.0 & 0.0 & 0.0 & 1 & 1.010 & -14.37 & 132 & 1 & 1.05 & 0.95 \\
\hline 6 & 1 & 0.0 & 0.0 & 0.0 & 0.0 & 1 & 1.010 & -11.34 & 132 & 1 & 1.05 & 0.95 \\
\hline 7 & 1 & 22.8 & 10.9 & 0.0 & 0.0 & 1 & 1.002 & -13.12 & 132 & 1 & 1.05 & 0.95 \\
\hline 8 & 2 & 30 & 30 & 0.0 & 0.0 & 1 & 1.010 & -12.10 & 132 & 1 & 1.05 & 0.95 \\
\hline 9 & 1 & 0.0 & 0.0 & 0.0 & 0.0 & 1 & 1.051 & -14.38 & 1 & 1 & 1.05 & 0.95 \\
\hline 10 & 1 & 5.8 & 2 & 0.0 & 0.19 & 1 & 1.045 & -15.97 & 33 & 1 & 1.05 & 0.95 \\
\hline 11 & 2 & 0.0 & 0.0 & 0.0 & 0.0 & 1 & 1.082 & -14.39 & 11 & 1 & 1.05 & 0.95 \\
\hline 12 & 1 & 11.2 & 7.5 & 0.0 & 0.0 & 1 & 1.057 & -15.24 & 33 & 1 & 1.05 & 0.95 \\
\hline 13 & 2 & 0.0 & 0.0 & 0.0 & 0.0 & 1 & 1.071 & -15.24 & 11 & 1 & 1.05 & 0.95 \\
\hline 14 & 1 & 6.2 & 1.6 & 0.0 & 0.0 & 1 & 1.042 & -16.13 & 33 & 1 & 1.05 & 0.95 \\
\hline 15 & 1 & 8.2 & 2.5 & 0.0 & 0.0 & 1 & 1.038 & -16.22 & 33 & 1 & 1.05 & 0.95 \\
\hline 16 & 1 & 3.5 & 1.8 & 0.0 & 0.0 & 1 & 1.045 & -15.83 & 33 & 1 & 1.05 & 0.95 \\
\hline 17 & 1 & 9 & 5.8 & 0.0 & 0.0 & 1 & 1.040 & -16.14 & 33 & 1 & 1.05 & 0.95 \\
\hline 18 & 1 & 3.2 & 0.9 & 0.0 & 0.0 & 1 & 1.028 & -16.82 & 33 & 1 & 1.05 & 0.95 \\
\hline 19 & 1 & 9.5 & 3.4 & 0.0 & 0.0 & 1 & 1.026 & -17.00 & 33 & 1 & 1.05 & 0.95 \\
\hline 20 & 1 & 2.2 & 0.7 & 0.0 & 0.0 & 1 & 1.020 & -16.80 & 33 & 1 & 1.05 & 0.95 \\
\hline 21 & 1 & 17.5 & 11.2 & 0.0 & 0.0 & 1 & 1.033 & -16.42 & 33 & 1 & 1.05 & 0.95 \\
\hline 22 & 1 & 0.0 & 0.0 & 0.0 & 0.0 & 1 & 1.033 & -16.41 & 33 & 1 & 1.05 & 0.95 \\
\hline 23 & 1 & 3.2 & 1.6 & 0.0 & 0.0 & 1 & 1.027 & -16.61 & 33 & 1 & 1.05 & 0.95 \\
\hline 24 & 1 & 8.7 & 6.7 & 0.0 & 0.043 & 1 & 1.021 & -16.78 & 33 & 1 & 1.05 & 0.95 \\
\hline 25 & 1 & 0.0 & 0.0 & 0.0 & 0.0 & 1 & 1.017 & -16.35 & 33 & 1 & 1.05 & 0.95 \\
\hline 26 & 1 & 3.5 & 2.3 & 0.0 & 0.0 & 1 & 1.000 & -16.77 & 33 & 1 & 1.05 & 0.95 \\
\hline 27 & 1 & 0.0 & 0.0 & 0.0 & 0.0 & 1 & 1.023 & -15.82 & 33 & 1 & 1.05 & 0.95 \\
\hline 28 & 1 & 0.0 & 0.0 & 0.0 & 0.0 & 1 & 1.007 & -11.97 & 132 & 1 & 1.05 & 0.95 \\
\hline 29 & 1 & 2.4 & 0.9 & 0.0 & 0.0 & 1 & 1.003 & -17.06 & 33 & 1 & 1.05 & 0.95 \\
\hline 30 & 1 & 10.6 & 1.9 & 0.0 & 0.0 & 1 & 0.992 & -17.94 & 33 & 1 & 1.05 & 0.95 \\
\hline
\end{tabular}

\section{AUTHORS' INFORMATION}

${ }^{1}$ Research Student, Brunel University, United Kingdom

Mohammad.shahrazad@brunel.ac.uk

${ }^{2}$ Senior Lecturer, Brunel University, United Kingdom

Ahmed.zobaa@brunel.ac.uk

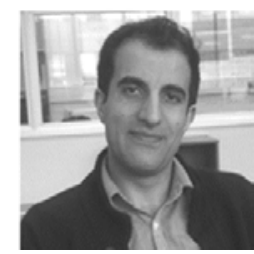

Mohammad Shahrazad was born in Iran in 1983. He received his B.Sc (Hons.) in electronics engineering from Broujerd Islamic Azad University, Iran in 2006. Also, he received his M.Sc. in Sustainable Electrical Power from Brunel University, United Kingdom in 2010. He is currently a Ph.D. student at Brunel University, United Kingdom. His research areas include FACTS and renewable energy.

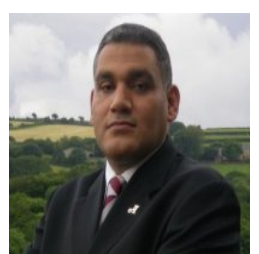

Ahmed Faheem Zobaa received the B.Sc.(Hons.), M.Sc., and Ph.D. degrees in electrical power and machines from Cairo University, Giza, Egypt, in 1992, 1997, and 2002, respectively. From 2007 to 2010, he was a Senior Lecturer in renewable energy with the University of Exeter, Cornwall, U.K. He was also an Instructor from 1992 to 1997, a Teaching Assistant from 1997 to 2002, and an Assistant Professor from 2003 to April 2008 with the Department of Electrical Power and Machines and the Faculty of Engineering, Cairo University, where he has also been an Associate Professor since April 2008. Currently, he is also a Senior Lecturer in power systems with Brunel University, Uxbridge, U.K. His main areas of expertise are lighting applications, power quality, (marine) renewable energy systems, grid integration, smart grids and energy management.

Dr. Zobaa is an Editor-in-Chief for the International Journal of Renewable Energy Technology. He is also an Editorial Board member, Editor, Associate Editor, and Editorial Advisory Board member for

many international journals. He is a registered Chartered Engineer, Chartered Energy Engineer, European Engineer, and International Professional Engineer. $\mathrm{He}$ is also a registered member of the Engineering Council U.K., Egypt Syndicate of Engineers, and the Egyptian Society of Engineers. He is a Fellow of the Institution of Engineering and Technology, the Energy Institute of U.K., the Chartered Institution of Building Services Engineers and the Higher Education Academy of U.K. He is a senior member of the Institute of Electrical and Electronics Engineers. $\mathrm{He}$ is a member of the International Solar Energy Society, the European Society for Engineering Education, the European Power Electronics and Drives Association, the British Institute of Energy Economics, and the IEEE Standards Association. 